\title{
REFERENCES
}

Fuchs.-Textbook of Ophthalmology (Duane). 1923.

Arch.f. Ophthal., Bd. LXXXVI, S. 155.

Gilbert.-Arch.f. Augenheilk., Vol. LXXXVIII, S. 143, 1921.

Treacher Collins.-Roy. Lond. Ophthal. Hosp. Reps., Vols. I-XII, p. 273.

Collins and Mayou.-Pathology of the Eye, p. 18.

Parsons.-Pathology of the Eye. Vol. I Part I, p. 322,

Morax.-Bull. de la Soc. Franc. d'Ophtal., Vol. XLIV, p. 365, 1931.

Houwer.-Trans. Ophthal. Soc. U.K., Vol. XLVIII, p. 167, 1928.

BOYD.-Pathology of Internal Diseases, p. 485.

MaCCALLUM.- Textbook of Ophthalmology, p. 995, 1928.

MASson -Bull. Assoc. Frang. pour l'Etude du Cancer, p. 303, June 20, 1921 ; Ann.d'Anat. Pathol., Vol. III, pp. 417, 657, 1926.

VERHOEFF.-Arch. of Ophthal., Vol. XL, p. 486, 1911.

SALZMANN.- Anatomy of the Human Eyeball, 1912.

HENKE and LUBARSCH.- - Handbuch der speziellen pathologischen Anatomie und Histologie. Erster teil, 11/1, S. 537, 1928.

\section{COLOBOMATA OF THE OPTIC NERVE SHEATH IN RATS}

\author{
BY \\ John V. V. Nicholls* and Katharine TANSLey \\ (FROM THE DEPARTMENT OF PHYSIOLOGY, \\ UNIVERSITY COLLEGE, LONDON)
}

AN examination of a collection of histological sections of rat eyes, prepared by one of us in connection with various investigations, disclosed some interesting examples of developmental defect about the optic nerve head. These were ectasias of the retina passing between the edge of the lamina cribrosa and the sclera into the optic nerve sheath, and might be considered as colobomata of the nerve sheath. Altogether sections through the optic nerve of 214 eyes were examined and most of these were serial sections. Ten cases presented this condition in greater or less degree, but showed certain differences from those described up to the present.

Quite an extensive literature has grown up around the whole subject of colobomata of the optic nerve. It is not our purpose, however, to deal with this in great detail. From our point of view it is interesting to note that Ginsberg (1896) reported a case in a rabbit showing a deep excavation of the optic nerve. A similar case in man, in which the lamina cribrosa was also defective was described by Goerlitz (1897). Von Hippel (1900) reported another, though more complicated case. Coats (1908) described two cases in an anencephalic monster where a pouch of retina ran through the lamina cribrosa into the substance of the optic nerve. In his paper, he summed up the whole question. While admitting the

\footnotetext{
*Travers Allen Travelling Fellow.
} 
difficulties, he attempted to classify colobomata of the optic nerve under three heads: (1) where the lesion is a coloboma of the choroid beneath the nerve, the nerve itself being normal and sharing only passively in the deformity; (2) where the lesion is a coloboma of the choroid and the nerve; (3) where the lesion is a coloboma of the nerve alone, the adjacent choroid being normal. Parsons and Coats (1906) reported a variation of type (3), in that, as well as there being retina in the optic nerve, the lamina cribrosa had given way at its temporal margin where an ectasia of the retina had occurred. The scleral margin was involved also at this point. More recently van Duyse (1919) and Calhoun (1930) have described somewhat similar cases.

Kayanagi (1921) found that when rabbits are inbred, individuals are often produced which have typical coloboma of the optic nerve. He studied this problem and found that the defect is inherited as a Mendelian recessive. By intensive inbreeding he was able to produce a pure stock and so could study all stages in the development of colobomata of the optic nerve. His specimens were of the same type as ours.

It is difficult to classify our ten cases as falling in any of Coats' three types. They are similar in some respects to Parsons and Coats' case, but should, we feel, form a fourth group, judging from the position of the ectasia and the path it has followed. In three of the cases, where the condition was most advanced (Fig. 2), little or no lamina cribrosa could be seen anywhere, and in some the nerve head had been pushed back, as it were, from the eye. The retina had penetrated between the nerve and sclera on all sides, to form a sort of sleeve about the nerve within its sheath. In seven eyes the condition was much less marked (Figs. 3 and 4), the lamina cribrosa, though deficient, had separated from the sclera at only one point where the retina had pocketed through under the vaginal sheath. In two other cases the lamina cribrosa had nowhere broken away, but was weak only, and the nerve head had been pushed back a little. In no case was there either pouching of the retina into the nerve substance itself or an associated coloboma of the choroid, also the central vessels of the retina were invariably in their normal position.

We also found one specimen of a different type of coloboma of the optic nerve. For this reason it has not been included in our series. In this specimen an ectasia had taken place to one side of the nerve and thinned sclera formed the outer covering. It contained remnants of retina but no choroid. The nerve head had been slightly displaced. It belongs to type (1) of Coats' classification. We present it merely for the sake of comparison.

The essential feature, then, of the series would seem to be the poor development of the lamina cribrosa. Parsons and Coats also 


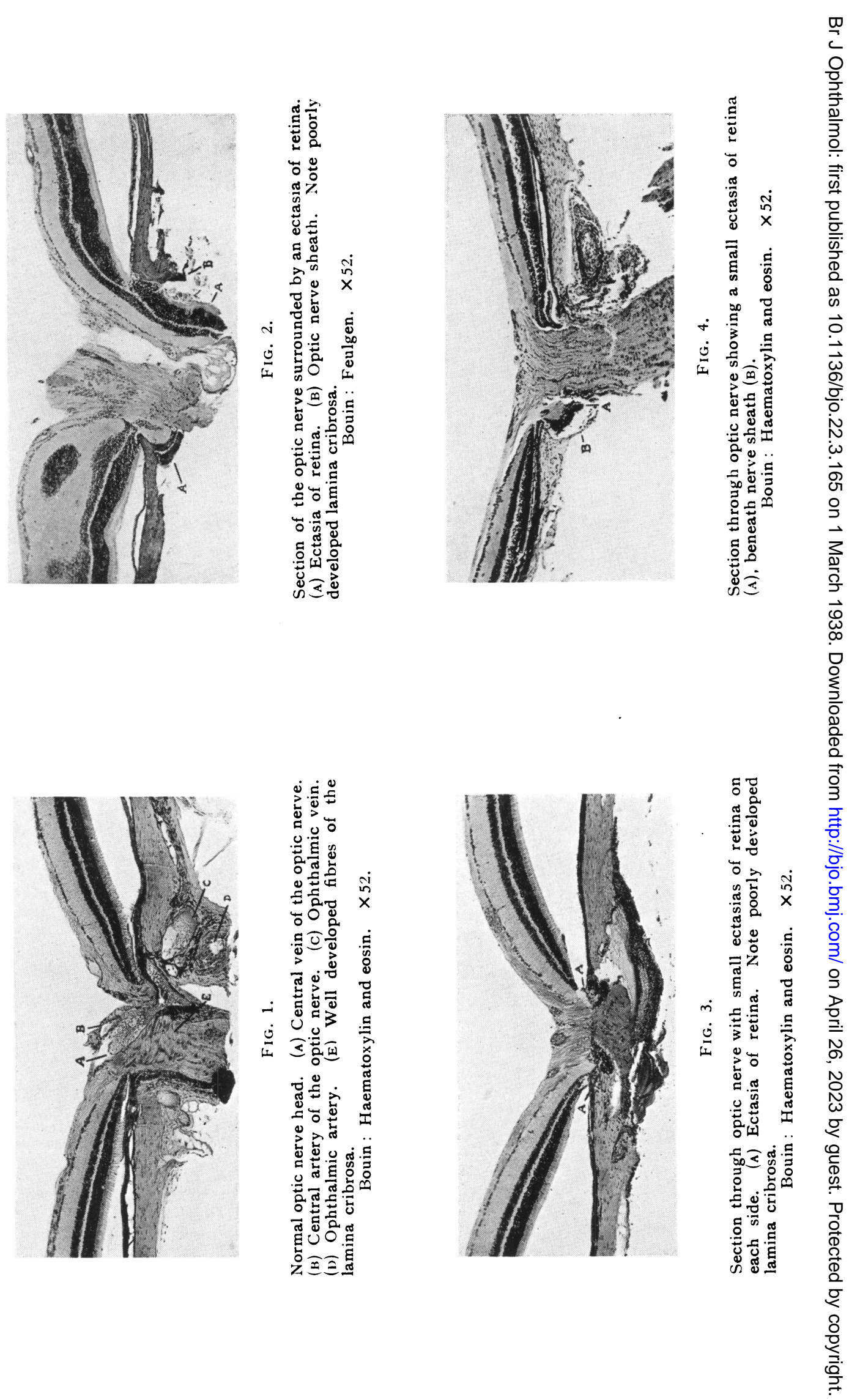


noticed the fragility of this structure in their case. There is some difficulty in evaluating the relationship of the ectasia to the weakness of the lamina cribrosa. Whether the ectasia follows upon the collapse of the lamina cribrosa as Parsons and Coats suggested, or both conditions are part of the same process is difficult to determine. Kayanagi's beautiful studies upon rabbits in this type of coloboma suggest the latter point of view. There is an abnormality in the condensation of the mesoderm about the neck of the primary optic vesicle so that small pouches of neural ectoderm are nipped off about the future nerve head. Because of, or along with this, there is poor development of the lamina cribrosa.

Under such circumstances it is not difficult to understand how the picture might become exaggerated as time progresses. Looked at in this way the two theories are not necessarily mutually exclusive. It also explains how in some of our cases we found the ectasia completely surrounding the optic nerve within its sheath. So far as we know this appearance has not been described before.

Coats emphasised two points in classifying colobomata of the optic nerve. Firstly, the relation of the ectasia to the intervaginal space; and secondly, the question of whether the nerve contains the central vessels. If the ectasia should approach the intervaginal space from the inner side, there must be a coloboma of the nerve; if from the outer, a coloboma of the adjacent choroid. Absence of vessels is evidence of maldevelopment, even though the nerve may have otherwise developed properly. It is also possible for the vessels to be in the normal position and yet for the cleft to be open. Thus there are exceptions to both rules. It is interesting to note, in this regard, that the vessels in all our specimens were normally placed, there was no evidence of an open nerve cleft, and the ectasia came down inside the sheath.

In one family of rats intensely inbred for the production of congenital retinal degeneration (Bourne, Campbell, and Tansley, 1938), these colobomata occurred in 5 out of 6 animals, thus showing an hereditary tendency in confirmation of Kayanagi's findings in rabbits. Those of our cases showing the most advanced condition also occurred among animals with retinal degeneration. One might be tempted to assume that there is some causal relationship between the two but the fact that colobomata of the optic nerve occur in some animals with no retinal degeneration, and that retinal degeneration usually takes place in the absence of any abnormality at the nerve head disproves this assumption.

Acknowledgments.--Our thanks are due to the Medical Research Council and the British Journal of Ophthalmology for grants 
which enabled this work to be done. We are also indebted to Dr. R. J. Lythgoe for the photographs.

\section{REFERENCES}

Bourne, M. C., Campbell, D. A., and Tansley, K.-Hereditary degeneration of the rat retina. Brit. Jl. Ophthal. (in press), 1938.

Calmoun, F. P.-Bilateral coloboma of the optic nerve. Arch. of Ophthal., Vol. III, p. 71, 1930.

Conts, G. - The pathology of coloboma at the nerve entrance. Roy. Lond. Ophthal. Hosp. Rep., Vol. XVII, p. 178, 1908.

Ginsberg, S.-Ueber die angeborenen Coloboma des Augapfels. Centrabl. $f$. prakt. Augenheilk., Bd. XX, p. 225, 1896.

Goerlitz, M.-Anatomische Untersuchung eines sogenannten Coloboma Nervi optici. Arch. f. Augenheilk, Bd. XXXV, p. 219, 1897.

KaYANaGI, Y.-Embryologische Untersuchungen ueber die Genese der Augenkoloboma und des Mikrophthalmus mit orbitalcyste. Arch.f Ophthal., Bd. CIV, p. 1, 1921.

Parsons, J. H., and CoATs, G.-A case of orbital encephalocele with unique malformation of the brain and eye. Brain, Vol. XXIX, p. 209, 1906.

van Duyse, G. M.-Colobomatous and Microphthalmic eyes. Brit. Jl. Ophthal., Vol. III, p. 529, 1919.

vON HIPPEL, E.-Graefe-Saemisch Handbuch des gesamt. Augenheilk., Pt. I, Vol. II, chap. IX, p. 27, 1900.

\section{THE APPARATUS OF PROFESSOR ARGAÑARAZ FOR EXTRACTION OF CATARACT BY THE SUCTION METHOD (PHAKOERISIS)}

THE apparatus designed by Professor Argañaraz for the operation of phakoerisis consists essentially of an ordinary glass 20 c.c. syringe (B) with its plunger (A), together with a rubber tube having moderately resistant walls (C), capable of occlusion or release by a clamp (D) and finally, the small suction cup or erisiphake (E). See Fig. 1.

The Syringe.-This is a glass syringe of 20 c.c. capacity which is capable of producing a vacuum of 5,10 or 15 c.c., representing a negative pressure of 30,50 or $70 \mathrm{~mm}$. $\mathrm{Hg}$. This vacuum can be regulated at will. If the clamp is closed and the piston withdrawn as far as the zero mark a vacuum of 15 c.c. is produced which is the longest possible with this size reservoir (A). If the plunger is only withdrawn as far as 3,5 or 10 c.c. corresponding intensities of negative pressure can be obtained.

In order to ensure that the system is hermetically sealed, it is essential to introduce a fair amount of sterilised lanoline or other suitable fat around the piston to prevent the infiltration of any air. Metal syringes are more costly and difficult to make than glass ones. They also change their shape slightly with repeated sterilisation and are harder to replace.

The retention clip (A).- This allows the piston to be fixed in 